Für Menschen scheinen noch kleinere Gaben dieses Farbstoffes (0,2 g) giftig zu sein. Ich kann deshalb mit dem Schlusse von J. Frentzel nicht übereinstimmen, dass „Mandarin wie Metanilgelb in den kleinen Dosen, in welchen es mit Nahrungs- und Genussmitteln während 24 Stunden in den menschlichen Körper gelangen kann, schwerlich, auch bei häufiger Aufnahme eine schädliche Wirkung äussern kann".

Zugleich widerlegen meine Versuche meines Erachtens nicht die Versuche von Th. Weyl, da ich kleinere Gaben der zu untersuchenden Farbstoffe verabreichte als Weyl und deshalb etwas andere Ergebnisse erhalten konnte.

J. Frentzel, der noch kleinere Dosen der Farbstoffe brauchte, denkt, wie es scheint, über seine Versuche anders.

Die Untersuchungen werden fortgesetzt.

\title{
Nachweis von extrahirtem Thee durch Sublimation.
}

\section{Von}

\section{Prof. Dr. A. Nestler in Prag.}

Durch die sehr bemerkenswerthen Untersuchungen 130 verschiedener Theesorten, welche seinerzeit im chemischen Untersuchungsamt in Dresden vorgenommen worden sind ${ }^{1}$, wurde zunächst für ein kleines Gebiet der Beweis geliefert, dass gegenwärtig eine Verfälschung des Thees durch Blätter anderer botanischer Herkunft oder durch Mineralstoffe zum Zwecke einer Gewichtserhöhung nicht mehr vorkommt; auch ein Zusatz von extrahirtem zu intaktem Thee wurde nach den genannten Untersuchungen nicht vorgefunden. In den letzten 4. Jahren hatte ich Gelegenheit, eine Anzahl von Theeproben durchweg minderwerthiger Qualität, welche in verschiedenen Gegenden Böhmens aus Kleinhandlungen entnommen worden waren, auf ihre Reinheit mikroskopisch zu prüfen, und kann jenen für Dresden angegebenen Befund im Allgemeinen bestätigen. Es waren durchweg echte Theeblätter und Fragmente derselben. Auch die chemische Untersuchung konnte keinen Anstand gegen dieselben erheben.

Nur eine einzige Art der Verfälschung wurde in 2 Fällen mit Sicherheit nachgewiesen. - Der als "Brakfast" bezeichnete Thee zeigte ein sehr ungleichmässiges Aussehen; er bestand aus (1.) bis 4 cm langen, gedrehten mehr oder weniger geradlinigen Stücken, ferner aus (2.) unregelmässig geknüllten oder gefalteten, sich hart anfühlenden, mitunter den unter (1) angeführten ähnlichen Theilen, welche aussen dunkelbraun, im Innern hellbraun waren; bisweilen zeigten dieselben cine glänzend braune Aussenseite; ausserdem wurden (3.) zahlreiche

1) A. Beythien, P. Bohrisch und J. Deiter: Beitrăge zur chemischen Untersuchung des Thees - Diese Zeitschr. 1900, 3, 145. 
rundliche bis erbsengrosse Gebilde mit rauher Aussenseite nachgewiesen, welche aus sehr kleinen. fest zusammenhängenden Fragmenten bestanden; auch verhältnissmässig \%ahlreiche Stieltheile wurden beobachtet.

Die unter (1) angeführten Bestandtheile erwiesen sich nach genauer Untersuchung als vollständig normal: es waren echte Theeblïtter oder Fragmente derselben mit Theïngehalt und ohne Zusatz einer anorganischen Substanz.

Die harten Stücke (2) dagegen liessen an der Aussenseite grosse Mengen von Stärkekleister erkennen, welcher namentlich nach Behandlung derselben mit warmem Wasser auf einem Objektträger mikroskopisch leicht nachweisbar war; nur ganz vereinzelt konnte ich unversehrte runde Stärkekörner von $48 \mu$ Durchmesser erkennen. Auch makroskopisch liess sich die Stärke nachweisen:

2-3 derartige, rerdächtige 'l'heestiicke wurden in einem Reagensglase mit ungefähr $2 \mathrm{ccm}$ Wasser etwas erhitzt und geschüttelt; nach Zusatz ron Jod wurde die Fliissigkeit dunkelblau. - . Der Nachweis von Thein durch Sablimamation (mittels Uhrglases und runder Glasplatte als Bedechung) lieferte ein negatives Ergebniss; es zeigte sich keine șpur einer Theïnnadel. - Diese Theefragnente konnten also mit Bestimmtheit als extrahirt und unter Anwendung von Stärkekleister zusammengeknüllt oder gefaltet bezeichnet werden. Dadurch erklärt sich die harte Beschaffenheit derselben und die bisweilen stark glänzende Aussenseite.

Jene mehr oder weniger runden Gebilde (3) zeigten ihrer Zusammensetzung entsprechend eine rauhe Aussenseite und bestanden aus sehr kleinen Theefragmenten, zahlreichen Trichomen des Theeblattes und anorganischen Fragmenten; alle diese Theile wurden gleichfalls durch Stärkekleister zusammengehalten. Diese Körner besitzen, wie mehrfache Versuche lebrten, Theïn, doch wahrscheinlich nur in geringer Menge, was nach ihrer Zusammensetzung begreiflich erscheint.

Das von mir ausgearbeitete Verfabren des direkten Nachweises von Theïn durch Sublimation ${ }^{1}$ ) zur Erkennung eines extrahirten Theeblattfragmentes bewährte sich sehr gut and führte rasch zum Ziele.

Unter Hinweis auf ein Referat in dieser Zeitschrift ${ }^{2}$ ) über „P. Kley, Nachweis von gebrauchtem Thee" möchte ich bei dieser Gelegenheit noch Folgendes hervorheben:

Ich selbst führte in meiner Untersuchung das Verfahren von Behrens für den Nachweis von Theïn durch Sublimation, welches nach Kley's Angabe die verschärfte und verbesserte Methode Blyth's ist, wörtlich an und bemerkte, dass dasselbe gewiss auch für kleine Theefragmente geeignet sei (vergl. S. 291 meiner Arbeit). - Sowohl Blyth wie Behrens fügen behufs Sublimation des

1) Diese Zeitschr. 1901, 4, 289.

) Diese Zeitschr. 1902, 5, 84 . 
Theïns dem Theeblatte gewisse Substanzen bei. - In jenem Referate heisst es weiter, dass Kley das Verfahren von Behrens derart ausgestaltet habe, dass $1 / 4$ bis $1 / 8$ eines Theeblattes genügt, um den beabsichtigten Nachweis mit voller Sicherheit zu führen, wobei noch der grösste Theil des zu prïfenden Blattes als Belegstïck erhalten bleibt, was bei Nestler nicht der Fall' ist".

Ich hatte bisher in meinen Versuchen nur solche Theeblattstücke angewendet, wie dieselben im Thee des Handels vorkommen, und hatte die Genauigkeit meines Verfahrens nicht bis anf die äusserste Grenze erprobt, weil mir das überflüssig erschien. Nun aber habe ich, angeregt durch jene Bemerkung, weitere Versuche angestellt und erfahren, dass jene einfache Methode des direkten Nachweises von Theïn an Genauigkeit nichts zu wünschen übrig lässt. Ich will nur einen von vielen Versuchen anfübren:

Ein Stückchen Pecco, ungefähr $1 \mathrm{~mm}$ lang und dick, genau 0,0011 g schwer, also gewiss ein sehr kleines Fragment, gab nach 10 Minuten des Versuches sehr zahlreiche Theïnnadeln ron durchschnittlich $16 \mu$ Länge.

Ich bemerke, dass ich, wie schon gesagt, zur Bedeckung der Uhrschale nunmehr stets eine runde Glasplatte verwende, weil dieselbe die mikroskopische Untersuchung wesentlich erleichtert.

\section{Referate.}

\section{Allgemeine Bestandtheile der Nahrungs- und Genussmittel.}

Adolf Jolles: Beiträge zur Kenntniss der Eiweisskörper. - Zeitschr. physiol. Chem. 1901, 32, 361-392.

Verf. bespricht zunächst die Ergebnisse, welche andere Forscher bei der Zersetzung der Eiweisskörper erhalten haben und theilt dann seine eigenen Versuche mit über den Abbau der Eiweisskörper mit Hilfe von Kaliumpermanganat in schwefelsaurer Lösung. Bei dieser Behandlung der Eiweisskörper tritt der Stickstoff hauptsächlich als Harnstoff, als durch Phosphorwolframsäure fällbare 'und als durch dieses Reageus nicht fällbare Substanz auf. Der Harnstoff kann hierbei nicht aus den Hexonbasen, welche von Kossel als der Kern der Eiweisskörper angesehen werden, entstanden sein, da djese bei der Oxydation mit Permanganat in saurer Lösung keinen Harnstoff liefern.

Von den untersuchten Eiweisskörpern gaben Oxyhämoglobin über $90 \%$ des Stickstoffs als Harnstoff ab, krystallisirtes Eieralbumin, krystallisirtes Serumalbumin, krystallisirtes Serumglobulin, Kaseïn, Vitellin aus Eigelb 70 bis $81 \%$, Fibrin und Vitellin aus Pflanzen 40 bis $50 \%$. Bei den beiden letzteren Eiweisskörpern fanden sich etwa $30 \%$ des Stickstoffs im Filtrate von der Phosphorwolframsäurefällung. Der Rest des Stickstoffs wurde im Phosphorwolframsäure-Niederschlage gefunden und dürfte im Wesentlichen auf den Grehalt an Hexonbasen zuräckzuführen sein.

Durch die Versuchsanordnung des Verf.'s ist ein Weg gefunclen, von den Eiweisskörpern zu demselben Endprodukt zu gelangen, welches als Endglied der Um- 